\title{
Diffusion of Iron Contained in Low Carbon Steel in Molten Aluminum
}

\author{
Chong Chul Yook
}

Dept. of Nuclear Engineering, College of Engineering, Hanyang University Seoul, Korea

Received Februay 1, 1967

Study on the diffusion of pure iron contained in $0.01 \% \mathrm{C}$ steel sphere in pure liquid aluminum was conducted under the tracer-diffusion equation and autoradiographical methods.

After the specimen was prepared by applying the sectioning technique, the activity of ${ }^{59} \mathrm{Fe}$ in aluminum was measured by autoradiography which was calibrated by the photographic density of X-ray films exposed to the standard source of ${ }^{60} \mathrm{Co}$-gamma rays and the activity was caused by intermittent neutron irradiation to the specimen.

Mathematical analysis in accordance with Fick's Law was performed using spherical coor. dinates and it is derived into equivalent concentration from chemical concentration into activity dose rate.

The values of diffusion coefficient were measured in the temperature range from $700 \mathrm{C}$ to $900^{\circ} \mathrm{C}$. The results were given by Arrhenius type equation as follows:

$$
D=2.57 \times 10^{-3} \exp \left(-\frac{4,600}{R T}\right) \mathrm{cm}^{2} / \mathrm{sec}
$$

where an activation energy and entropy term were calculated from the linear portion of the above Arrhenius plots.

As a result, it was known that the rate of $\mathrm{Fe}$ diffusion into $\mathrm{Al}$ was ten times faster for $0.01 \%$ low carbon steel with comparatively high content of $\mathrm{Mn}(0.813 \%)$ and low content of $\mathrm{Si}(0.009 \%)$ than those of higher content of carbon $(-0.1 \% \sim 0.2 \%)$ and low content of $\mathrm{Mn}$ $(0.048 \%)$.

\section{Introduction}

The principal aim of this paper is to determine the diffusion coefficients of iron contained in low carbon steel in liquid aluminum after the autoradiographical method.

The problem concerning the diffusion of solid iron into the liquid aluminum bears importance in the practical industrial application of metallurgy of aluminum and its alloy, for example, in the process of a cylinder in a combustion engine. A very small amount of $\mathrm{Fe}$ concentration in aluminum has a close relation to its physical properties.

In order to determine a diffusion coeffcient of b.c.c. low carbon $(0.01 \%)$ steel in liquid aluminum, annealing was adopted in temperature range from $700^{\circ} \mathrm{C}$ to $900^{\circ} \mathrm{C}$.

In this particular diffusion species, the diffusion mechanism takes place by vacancy mechanism and interstitial mechanism which is already known.

The interstitial diffusion coefficient conforms to an equation of the temperature dependence of the diffusion coefficient $D$ and fits and Arrhenius type relation ${ }^{1}$.

$$
D=D_{0} \exp \left(\begin{array}{c}
Q \\
R T
\end{array}\right)
$$

where $D_{0}$ is the entropy term, $Q$ is the experimental activation energy for diffusion, $R$ is the universal gas constant and $T$ is the absolute temperature in diffusion anneal.

The results in this diffusion for the particular species under the steady state condition of annealing are obtained:

$$
\begin{aligned}
D_{0} & =2.57 \times 10^{-3} \mathrm{~cm}^{2} / \mathrm{sec} \\
Q & =4,600 \mathrm{cal} / \mathrm{mole}
\end{aligned}
$$

To determine the diffusion coefficients, the autoradiographical method was applied after cutting samples into various types of section.

The activity of each specimen which originates in the $(n, \gamma)$ reaction from the con- 
centrated $\mathrm{Fe}$ atom in aluminum was measured after intermittent neutron irradiation ${ }^{2)}$ in the TRIGAR MARK-II REACTOR.

Commercial X-ray films were exposed to detect gamma activity of the sample and the photodensity was measured to convert it into activity, while they were correlated with the standardization of photodensity by using ${ }^{137} \mathrm{Cs}$ and ${ }^{60} \mathrm{Co}$ standard source.

Those activities measured for the specimen are shown on the semilog paper by applying tracer-diffusion equation ${ }^{3 \sim 5)}$.

$$
A(x, t)=\frac{A_{0}}{(\pi D t)^{1 / 2}} \cdot \exp \left(\frac{-X^{2}{ }_{n}}{4 D t}\right)
$$

The equation ( 2 ) is also called thin film solution and Fick's equation for volume diffusion, where $A(x, t)$ is the concentration of specific gamma activity of ${ }^{59} \mathrm{Fe}$ diffused into section of the specimen, $x$ is the distance between the center of the specimen or the boundary between $\mathrm{Fe}$-sphere and $\mathrm{Al}$, and the surface. $A_{0}$ is the activity of the ${ }^{59} \mathrm{~F}$ tracer deposited originally, $t$ the diffusion annealing time, and $D$ the diffusion coefficient.

From the equation

$$
\frac{A_{0}}{(\pi D t)^{1 / 2}}=(\text { constant }) \text { when } \mathrm{X}^{2}=0
$$

The gradient after plotting $\log A$ versus $\mathrm{X}^{2}$ (penetration plot) were linear and equal to

$$
b=\frac{1}{4 D t}
$$

Diffusion coefficient $D$ is determined by this gradient $b$.

Mathematical analysis for the diffusion of solute through the wall of spherical solid particles was made and its application to the field of iron-graphite powder metallurgy was studied $^{6}$. Rules obtained through these experiments are considered useful for this paper.

\section{Theoretical Foundation}

Fick's Second Law concerns the basic equation for the experimental study of isothermal diffusion. It is useful for this study under the assumption of spherical diffusion model.

Fick's Second Law is;

$$
\frac{\partial C}{\partial t}=D\left(\frac{\partial^{2} C}{\partial r^{2}}+\frac{2}{r} \cdot \frac{\partial C}{\partial r}\right)
$$

In the spherical coordinate in the steady state, equation becomes

$$
\frac{\partial^{2} C}{\partial r^{2}}+\frac{2}{r} \cdot \frac{\partial C}{\partial r}=0
$$

where

$$
\begin{aligned}
C= & \text { Concentration of } \mathrm{Fe} \text { solute space } \\
& \text { atom } \\
r= & \text { radius of spherical coordinate } \\
D= & \text { diffusion coefficient of solute iron } \\
& \text { in liquid aluminum }
\end{aligned}
$$

The concentration of $\mathrm{Fe}$ at the surface of Fe steel ball is $C_{1}$ and the concentration of $\mathrm{Fe}$ at the end of a spherical wall of aluminum is $C_{2}$, where $C_{1}>C_{2}$.

Diameter of $\mathrm{Fe}$ steel ball and aluminum are $2 a$, and $2 b$, where $2 a=1 \mathrm{~cm}, 2 b=5 \sim 7.7 \mathrm{~cm}$. The region $a \leq r \leq b$ is defined in this experimental set up and the concentration approaches the steady-state distribution.

Since the gradient of $\mathrm{Fe}$ concentration is $(\partial C / \partial r)_{r=b}$ at $r=b$, the total amount in spherical wall in time $t$ is $Q_{t}$ :

$$
\begin{aligned}
Q_{t}= & \int_{0}^{t} D\left(\frac{\partial C}{\partial r}\right)_{r=b} d t=B_{0}\left[\frac{1}{6}-\frac{D t}{(b-a)^{2}}\right. \\
& \left.+\frac{2}{\pi^{2}} \sum_{n=1}^{\infty} \frac{(-1)^{n}}{n^{2}} \exp \left\{-\frac{n^{2} \pi^{2} D t}{(b-a)^{2}}\right\}\right] \quad
\end{aligned}
$$

where

$$
B_{0}=\frac{a}{b}(a-b)\left(C_{1}-C_{2}\right), n=1,2,3 \cdots \cdots \cdots \cdots
$$

practically, $b \gg a$ and $C_{2} \fallingdotseq 0$ as the boundary condition in this experiment. From this condition, equation (7) becomes

$$
\begin{aligned}
Q_{t} \simeq & C_{1} a\left[\frac{1}{6}-\frac{D t}{b^{2}}+\frac{2}{\pi^{2}} \sum_{n=1}^{\infty} \frac{(-1)^{n}}{n^{2}} \times\right. \\
& \left.\exp \left\{-\frac{n^{2} \pi^{2} D t}{b^{2}}\right\}\right]
\end{aligned}
$$

Simplifying equation (8) further, when the higher order terms more than $n=2$ are able to be negligible, we have

$$
Q_{t} \simeq C_{1} a\left[\frac{1}{6}-\frac{D t}{b^{2}}-\frac{2}{\pi^{2}} \exp \left(-\frac{\pi^{2} D t}{b^{2}}\right)\right]
$$

In the mean time, the small amount of increase of $\mathrm{Fe}$ concentration is expressed by

$$
C_{2}=\frac{4 \pi b^{2} Q_{t}}{V}
$$

where $V$ is the volume of aluminum. 
The effects of change of $C_{2}$ upon the calculation of the diffusion coefficient of iron in liquid aluminum could be considered to be small in this diffusion model.

For diffusion experiment utilizing a radioactive tracer which we have performed, mathematical description should be idealized as shown in the equation and the concentration $Q_{t}$ shown in equation (9), (10) could be expressed as

$$
\begin{aligned}
Q_{t}= & \frac{A_{0}}{(\pi D t)^{1 / 2}} \text { when } X=0 \\
C= & A\left(\text { equivalent activity of }{ }^{59} \mathrm{Fe}\right. \text { con- } \\
& \quad \text { centration at } X)
\end{aligned}
$$

\section{Experiments and Results}

Both $300 \mathrm{~g}$ and $500 \mathrm{~g}$ of pure aluminum (chemical compositon wt $\%$ : $\mathrm{Al}: 99.7 \%, \mathrm{Fe}$ : $0.2 \%, \mathrm{Si}: 0.1 \%$ and other traces) were charged in a graphite crucible of No. 2 and No. 4 in size, and the smelted aluminum was stirred with $\mathrm{LiCl}-\mathrm{NaCl}-\mathrm{ZnCl}_{2}$ powder mixed in the ratio of 3:1:2 in order to prevent any forming defect in the alloy to be caused by oxidizing.

The surface of liquid aluminum was covered with the flux of about $1 \mathrm{~cm}$ thickness composed of $40 \% \mathrm{NaCl}, 30 \% \mathrm{KCl}, 20 \%$ charcoal powder and $10 \% \mathrm{LiCl}_{2}$.

The liquid aluminum was kept at the steady state temperature for each diffusion anneal.

Before dipping a spherical iron sample of $1 \mathrm{~cm} \mathrm{dia}$. into liquid aluminum, the specimen was washed quickly in concentrated $\mathrm{HCl}$ acid for removing oxide films and rinsed.

The rinsed specimen was brushed in a solution composed of $25 \mathrm{~g} \mathrm{Na}_{2} \mathrm{CO}_{3}, 25 \mathrm{~g} \mathrm{Na}_{3}$. $\mathrm{PO}_{4}, 20 \mathrm{~g} \mathrm{NaOH}$ and 1 liter $\mathrm{H}_{2} \mathrm{O}$ in order to remove grease and dust from the specimen.

After rinsing, it was dried in the oven at 60-80 C.

The chemical composition of low carbon steel ball is $0.01 \% \mathrm{C}, 0.008 \% \mathrm{P}, 0.009 \% \mathrm{~S}, 0.014 \%$ $\mathrm{Si}, 0.813 \% \mathrm{Mn}$ and $99.148 \% \mathrm{Fe}$.

The weight of the iron sphere is $12 \mathrm{~g}$ and its diameter is $1 \mathrm{~cm}$. A spherical iron specimen was hung with $1.8 \mathrm{~mm}$ diameter of stainless steel wire and the geometrical experimental installation is shown in Figs. 1 and 2.
In exposing the surface of the stainless steel wire in the heat, it was coated with a heat resistance material composed of $\mathrm{Al}_{2} \mathrm{O}_{3}$, water glass and $\mathrm{H}_{2} \mathrm{O}$ with the ratio of $2: 1: 1$ in weight, and then it was dried.

Before putting the Fe specimen into liquid aluminum, the melt was stirred for one minute, with a stainless steel bar coated with magnetic cover of $\mathrm{Al}_{2} \mathrm{O}_{3}$ layer.

As soon as the $\mathrm{Fe}$ specimen was immersed and placed in the liquid aluminum, the flux should be covered on the surface of aluminum.

The specimen was kept static (in a still condition) during the diffusion annealing time at each temperature of the diffusion run.

To indicate the annealing temperature, the Rh-Pt thermocouple was used with lead wire which was adjusted at the cold zero point. The thermocouple having $0.2 \%$ error in this diffusion experiment, was connected with the pyrometer having $3^{\circ} \mathrm{C}$ error which in turn connected with the relay and then finally to the transformer, as shown in Fig. 1.

The heating system used was an electricfurnace of $2.5 \mathrm{~kW}$ capacity, and five succes-

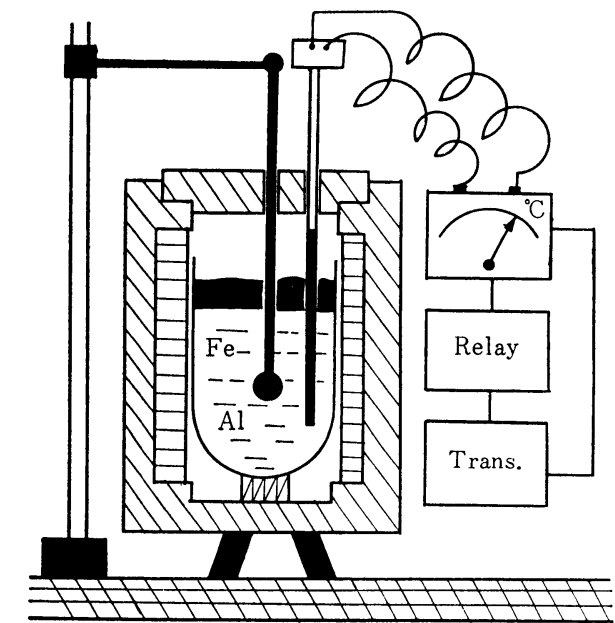

Fig. 1 Lay out diagram for diffusion experiment. sive diffusion runs were performed at $700^{\circ} \mathrm{C}$, $750^{\circ} \mathrm{C}, 800^{\circ} \mathrm{C}, 850^{\circ} \mathrm{C}$ and $900^{\circ} \mathrm{C}$ in atmospheric pressure.

Turning off the heat source after the rated operation time of 10 minutes, the specimen was then cooled rapidly with cold air or cold water. The specimen was ready to be cut into various shapes of section, i.e., into 
two equal pieces with the Fe-steel ball in the center or without the Fe-steel ball in test samples, square shapes without a ball of $0.4 \mathrm{~cm}$ thickness.

The first cutting was made from the center of the Fe-ball and the second cutting was made from the boundary of the Fe-ball and Al.

These cuts and sectioned specimens were irradiated for activation by thermal neutron flux of $0.877 \times 10^{12}$ neutrons $/ \mathrm{cm}^{2} / \mathrm{sec}$.

The activity was caused by the $(n, \gamma)$ reaction for the $\mathrm{Fe}$ atoms in the $\mathrm{Fe}-\mathrm{Al}$ diffusion solid specimen.

The activated ${ }^{59} \mathrm{Fe}$ in aluminum was measured by autoradiography after three hours of decaying of the surface contaminated activity and impurity on the specimens.

Autoradiographical films used were commercial Fuji X-ray films and the exposure time has been from 10 to 30 minutes by detecting the amount of activity from the specimen with the precision type juno survey meter.

The film to be exposed were tightly contacted with the specimen by pressing with lead block, which was necessary to protect scattered gamma radiation which in turn would increase sensitivity.

In order to secure high sensitivity of films, they were covered with the lead leaf at the same time.

To develop films after exposure, the standardizing film had to be prepared beforehand and the films should be developed with the same time duration and in the same developing conditon.

The standardizing films were prepared by irradiating it with the ${ }^{60} \mathrm{Co}$ ( $5 \mathrm{~m}$ curies) gamma ray standard source which has almost same energy value as that of ${ }^{59} \mathrm{Fe}$ gamma rays.

For standardization, the dose rate for a ${ }^{60} \mathrm{Co}$ source was calculated from the following formula:

$$
R(\mathrm{R} / \mathrm{hr})=\frac{13.6 A\left(\mathrm{mCi} \text { of }{ }^{60} \mathrm{Co}\right)}{d^{2}\left(\mathrm{~cm}^{2}\right)}
$$

where $d$ is distance between the standard source and films, $A$ is activity of the ${ }^{60} \mathrm{Co}$ gamma ray source and $R$ is the dose rate.

In corporation with the equation (12), five standard films were prepared for five values of activity of $0,50,100,200$ and $300 \mathrm{mR}$ at various rating exposure times. The films exposed to test specimens and those exposed to the standard gamma ray source were developed at the same time duration and in the same condition of developing solution.

Both the activity and the photodensity of the standardized films were measured and then the activity-photodensity relation plots were made for each of the testing diffusion specimen. The plots were observed to show linear relation between photodensity and activity.

The activity of test specimens is also dependent on the penetration distance of ${ }^{59} \mathrm{Fe}$ between the center of an Fe steel ball or the surface of the Fe-Al boundary and the surface wall of aluminum.

Photodensity measured at each spot on the film $0.2 \mathrm{~cm}$ interval could then easily be converted into activity by using the plots.

The $0.2 \mathrm{~cm}$ distance intervals were examined with the films in the horizontal ( $X$-axis) and vertical directions ( $Y$-axis) as shown in Fig. 2. Here the distance in both directions is equivalent to spherical radius of $r$ in equations (7) and (8).

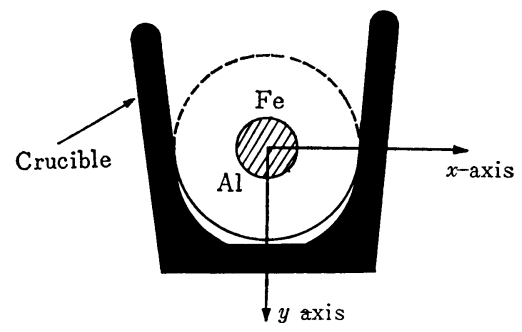

\begin{tabular}{lcc}
\multicolumn{3}{c}{ Experimental geometry } \\
Fe & $\mathrm{Al}$ \\
Weight & $12 \mathrm{~g}$ & $30.7500 \mathrm{~g}$ \\
Dia. & $1.0 \mathrm{~cm}$ & $5 \sim 7.7 \mathrm{~cm}$ \\
Low carbon & steel ball composition \\
$\mathrm{C}-0.01 \%$ & $\mathrm{Si}-0.014 \%$ \\
$\mathrm{P}-0.008 \%$ & $\mathrm{Mn}-0.813 \%$ \\
$\mathrm{~S}-0.009 \%$ & $\mathrm{Fe}-99.148 \%$ \\
Pure aluminum in composition \\
Al-99.7\% \\
$\mathrm{Si}-0.1 \%$ \\
Fe-0.2\% \\
Fig. 2 Geometry of the diftusion model.
\end{tabular}


Activity versus distance square $\left(\mathrm{cm}^{2}\right)$ plot is shown in Fig. 3 in which diff usion penetration plot for the $X$-axis and $Y$-axis are separately plotted and it utilized the equation (3). Actually Fig. 3 represents the case when Fe steel ball is included in the test sample and the diffusion from the center of Fe steel ball up to the boundary of Fe-Al is shown by the points marked by $1,2,3,4,5, \cdots$.

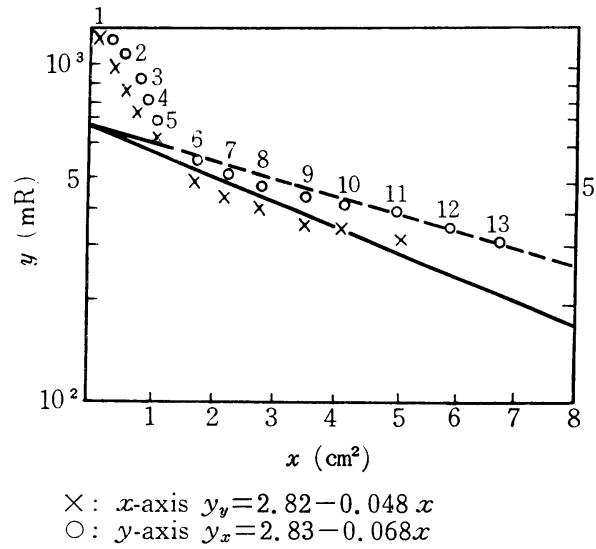

Fig. 3 Diffusion penetration plot along $x$ and $y$-axis. Notice that the internal diffusion of $\mathrm{Fe}$ (points 1 5) is also shown.

The temperature dependence and directional variation of diff usion are demonstrated in Figs. 4 and 5 respectively.

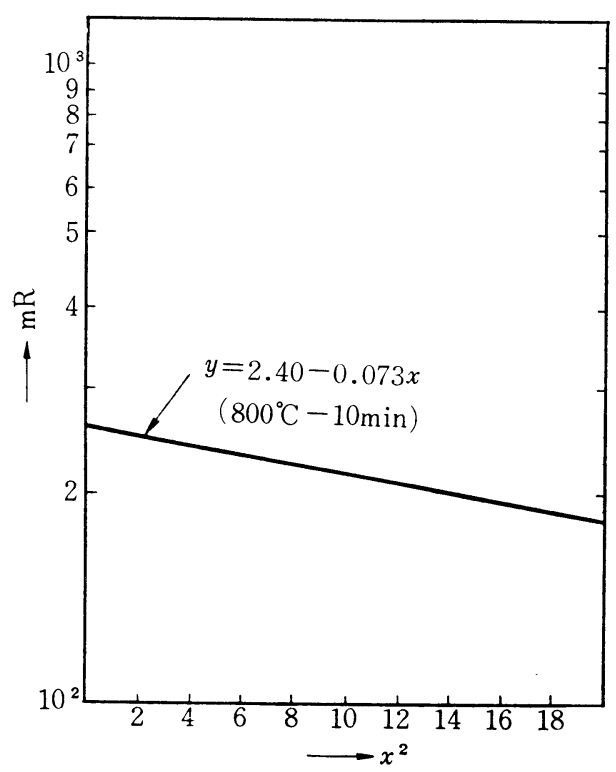

Fig. 4 Diffusion gradient for $\mathrm{Al}$ only.

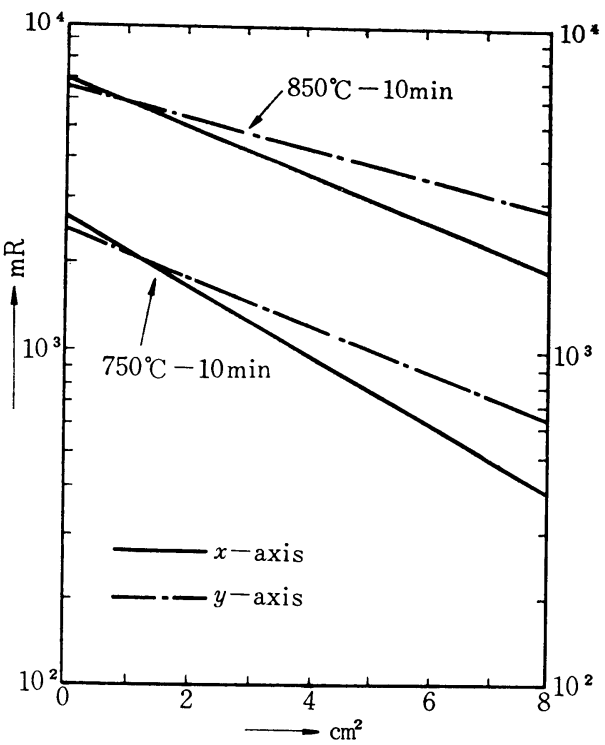

$$
\begin{aligned}
750^{\circ} \mathrm{C}: & y_{x}=2.38-0.099 x \\
& y_{y}=2.36-0.072 x \\
850^{\circ} \mathrm{C}: & y_{x}=2.36-0.068 x \\
& y_{y}=2.82-0.048 x \\
& \text { Temperature dependence of } \\
& \text { diffusion }
\end{aligned}
$$

Fig. 5 Directional temperature gradient along $x$ and $y$-axis.

Both of the figures are plotted for the case when the test body is consisted of only $\mathrm{Al}$, namely the sample is cut perpendicular to the $x$-axis at the Fe-Al boundary.

In Figs. 4 and 5 we have drawn the tracerdiffusion Eq. (2) in terms of $X$ and $Y$ defined as

$$
\begin{aligned}
& X=x^{2} \\
& Y=\log A(x, t),
\end{aligned}
$$

namely the linear relation

$$
\begin{aligned}
& Y=a+b X \\
& a=\log \frac{A_{0}}{(\pi D t)^{1 / 2}} \quad \text { and } b=-\frac{1}{4 D t} .
\end{aligned}
$$

In determining the most probable values for $a$ and $b$, we have employed the least square method.

Figure 4 is plotted for the case when the test body is consisted of Al only, namely the sample is cut perpendicular to the $x$-axis at the Fe-Al boundary, while Fig. 5 is for the case when the test body contains both $\mathrm{Fe}$ and $\mathrm{Al}$, namely the sample is cut perpendicular to the $X$-axis at the center of $\mathrm{Fe}$ ball. 
While Fig. 4 represents the diffusiongradient line along $X$-axis only, we have plotted both the $x$ - and $y$-directional diffusiongradient liner in Fig. 5. In the figure we observe that the two lines almost coincide for small distances and have slight difference in the value of gradient.

Fig. 6 shows the experimental diffusion plot to obtain the activation energy $Q$ and entropy term $D_{0}$ which could determine the value of $D$ in the Arrhenius type equation (1). Here the dependent variable is $\log D$, the independent variable is $1 / T$, while the ordinate intercept is $\log D_{0}$. The value of $Q$ is then determined by measuring the value of slope as shown in Eq. (1). In light of the above conclusion we can regard $X$-axis as representing general direction $r$.

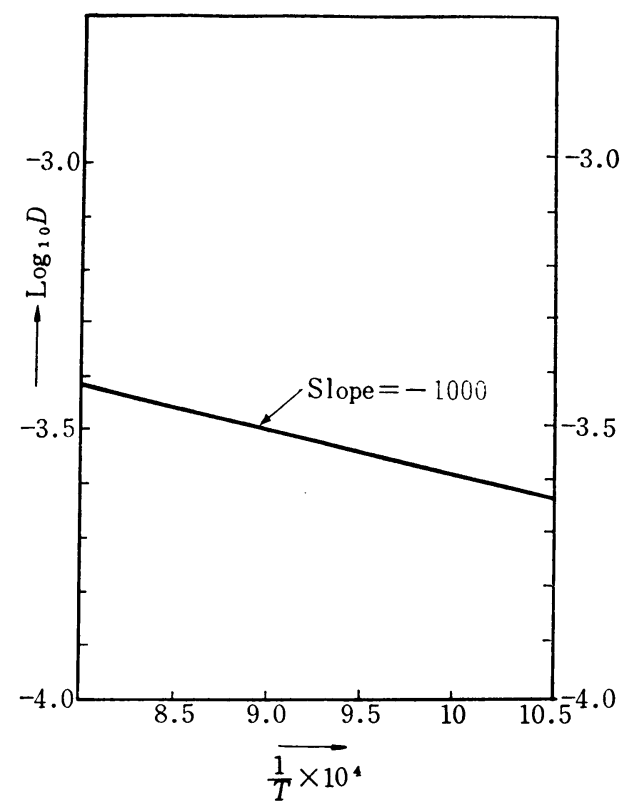

Fig. 6 Experimental diffusion data plotted to obtain the activation energy $Q$ and entropy term $D$.

The values of $D_{0}$ and $Q$ obtained in the above way turns out to be:

$$
\left.\begin{array}{l}
D_{0}=2.57 \times 10^{-3} \mathrm{~cm}^{2} / \mathrm{sec} \\
Q=4.60 \mathrm{cal} / \mathrm{mole} .
\end{array}\right\}
$$

In Table (1) we have listed the necessary data to determine the diffusion coefficients.

From the values of $D$ given in Table 1 we can easily find out the dependence of diffusion coefficient for the test body consisting of solid $\mathrm{Fe}$ immersed in Al liquid when 10 minutes of annealing time is given for each of the temperature shown. In the above the annealing temperature correction was made for each diffusion run.

Table 1 Temperature dependence of diffusion coefficients

\begin{tabular}{c|c|c|c}
\hline $\begin{array}{c}\text { Temp. } \\
{ }^{\circ} \mathrm{K}\end{array}$ & $\begin{array}{c}\text { Diffusion } \\
\text { coefficient } \\
D\end{array}$ & $\frac{1}{T}$ & $\log D$ \\
\hline 700 & $2.5 \times 10^{-4}$ & $10.15 \times 10^{-4}$ & -3.602 \\
\hline 750 & $2.8 \times 10^{-4}$ & $9.75 \times 10^{-4}$ & -3.552 \\
\hline 800 & $3.0 \times 10^{-4}$ & $9.33 \times 10^{-4}$ & -3.523 \\
\hline 850 & $3.3 \times 10^{-4}$ & $8.93 \times 10^{-4}$ & -3.482 \\
\hline 900 & $3.6 \times 10^{-4}$ & $8.50 \times 10^{-4}$ & -3.444 \\
\hline
\end{tabular}

It is important to notice that the time calibration may effect the diffusion coefficient which was caused by time delay in heating and cooling?).

For this reason the diffusion time correction should be made for all cases. Under the steady state condition, the relationship between the diffusion coefficient in log scale and $1 / T\left({ }^{\circ} \mathrm{K}\right)$ is shown in Fig. (7), which have been drawn according to the data shown in Table 1.

In Table 2 we have listed the measured values of $X$ and $Y$, where

$$
\begin{aligned}
& X=x^{2} \\
& Y=\log D_{t},
\end{aligned}
$$

against the number of values of temperature shown.

If we put

$$
a=\log D_{0} \text { and } b=-\frac{Q}{R T}
$$

in Eq. (1) we have

$$
Y=a+b X
$$

where $a$ and $b$ should be determined empirically from the listed values of $X$ and $Y$ in Table 2. By employing the least square method as before we obtained

$$
Y=9.20-0.662 X
$$

This result has been plotted in Fig. 7 .

In determining the value of $\log D$ we have to consider the error in $D$ due to pyrometer and thermocouple, and it was found that the error is estimated to be $3 \%$ due to $\pm 5^{\circ} \mathrm{C}$ uncertainty in the temperature measurements. 
Table 2 Determination of linearity relation between $X$ and $Y$

\begin{tabular}{|c|c|c|c|c|c|}
\hline No. & ${ }^{\circ} \mathrm{C}$ & $X\left(\frac{1}{T}\right)$ & $X^{2}\left(\frac{1}{T}\right)^{2}$ & $Y(D)$ & $X Y\left(\frac{D}{T}\right)$ \\
\hline 1 & 900 & 8.5 & 72. 25 & 3. 6 & 30.60 \\
\hline 2 & 850 & 8. 92 & 79. 74 & 3. 2 & 28.54 \\
\hline 3 & 800 & 9. 34 & 87. 23 & 3. 1 & 28. 95 \\
\hline 4 & $75 \mathrm{u}^{\circ}$ & 9. 75 & 95.06 & 2.6 & 25.83 \\
\hline 5 & 700 & 10. 15 & 103. 02 & 2.5 & 25.88 \\
\hline 6 & & $\Sigma X=4.6 .6$ & $\sum X^{2}=437$ & $\sum Y=15.1$ & $\begin{array}{c}\sum X Y= \\
139.81\end{array}$ \\
\hline 7 & & $\begin{array}{r}\left(\sum X\right)^{2}= \\
2178\end{array}$ & & & \\
\hline & $\begin{array}{l}Y= \\
a= \\
b=\end{array}$ & $\begin{array}{l}\frac{a+b X}{\sum X \sum X Y} \\
\left(\sum X\right) \\
\frac{\sum X \sum Y}{\left(\sum X\right)^{2}-} \\
Y=9.20\end{array}$ & $\begin{array}{l}\frac{-\sum Y \sum X^{2}}{-n \sum X^{2}} \\
\frac{n \sum X Y}{n \sum X^{2}}=- \\
-0.662\left(\frac{1}{T}\right)\end{array}$ & $\begin{array}{l}=9.20 \\
0.662\end{array}$ & \\
\hline
\end{tabular}

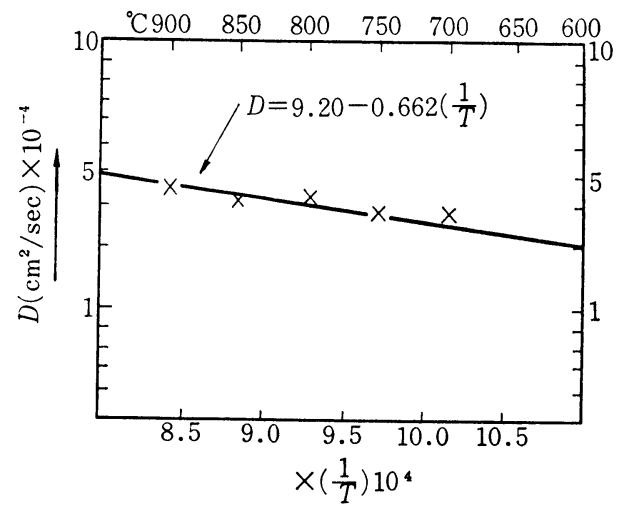

$$
\begin{aligned}
D_{t} & =D_{0} \exp \left(-\frac{Q}{R}\right)\left(\frac{1}{T}\right) \quad D_{0}=2.57 \times 10^{-3} \\
D_{900} & =D_{0} \exp (-4600 / 2 \times 1173)=3.6 \times 10^{-4} \\
D_{850} & =D_{0} \exp (-4600 / 2 \times 1123)=3.3 \times 10^{-4} \\
D_{800} & =D_{0} \exp (-4600 / 2 \times 1073)=3.0 \times 10^{-4} \\
D_{750} & =D_{0} \exp (-4600 / 2 \times 1023)=2.7 \times 10^{-4} \\
D_{700} & =D_{0} \exp (-4600 / 2 \times 973)=2.4 \times 10^{-4}
\end{aligned}
$$

Fig. 7 Arrhenius plots for diffusion showing temperature dependence of the diffusion coefficient for pure iron in aluminum.

The solidifying temperature was measured to be $660^{\circ} \mathrm{C}$ by our Pt-Rh thermocouple which was adjusted at the cold point zero.

\section{Conclusion}

The value of $D$ for the given $1 / T$ was obtained by the least square analysis from the data given was listed in Table 1.
They are plotted in Figs. 4 and 5 in the manner to show the linearity character of log $D$ against $1 / T$.

In our experimental installation it is assumed that penetration distance $r$ of $\mathrm{Fe}$ atom in equation (5) and (6) to be equivalent to as that along the $x$-axis.

The diffusion coefficient $D$ for the low carbon $(0.01 \% \mathrm{C})$ in the "Still" condition is determined by the experimental process at various temperatures.

The gradient, $1 / 4 D t=b$ were obtained, for example, from Figs. 4 and 5. Time correction was made for the diffusion annealing time $t$ and it was found that time correction were $88 \mathrm{sec}$ for $700^{\circ} \mathrm{C}$ and $800^{\circ} \mathrm{C}$ and $116 \mathrm{sec}$ for $900^{\circ} \mathrm{C}$.

The activation energy $Q$ and entropy term were determined from Fig. 6 .

With these experimental diffusion data, the value of $D$ determined from the Arrhenius type equation (1) turns out to be :

$$
D=2.57 \times 10^{-3} \exp \left(-\frac{4,600}{R T}\right) \mathrm{cm}^{2} / \mathrm{sec}
$$

The error involved in the value of $D$ was about $3 \%$ for the temperature range of $700^{\circ} \mathrm{C}$ $900^{\circ} \mathrm{C}$ and could in most cases be neglected. However, Okkerses) reported that this error to be about $4 \%$ for general cases. It is noticed that for low carbon content $(0.01 \%)$, the diffusion concentration rate $D$ takes a significantly high value. This is a well known result that the $\mathrm{Fe}$ atom easily penetrates into aluminum when it has low carbon content.

The main reasons for obtaining high values of $D$ are interpreted as follows:

1. The value of $\log D$ increases linearly with decreasing carbon content ${ }^{9}$. In our experiment, the carbon content in the sample iron was $0.01 \%$ a value so small that it affects the value of $D$ in a predominant way.

2. Transport control (local equilibrium), the so called "Up hill"10,11) diffusion might take place in our experiment according to which comparatively high content of $\mathrm{Mn}(0.813 \%)$ and low content of $\mathrm{Si}(0.009 \%)$ in the solute iron causes a fast rate of diffusi- 
bility. It is important to notice the fact that the low carbon content made it easy for solute iron to transport through the matrix of aluminum base.

It is considered that further research is hoped regarding the behavior the $\mathrm{Mn}$ atom with the low carbon solute iron in the aluminum base.

The diffusion coefficient for the "stirring" or "rotating" condition may take a considerably different values, but we have not performed the experiment for that case.

\section{Acknowledgment}

The author, first of all, wishes to express his sincere gratitude to the Hanyang University authorities who provided him with all necessary instruments for this experiment. The author's thanks also go to Dr. J.Y. Choi for his valuable suggestions and discussions regarding this study, and to Prof. C.S. Choi for his kind arrangement of samples for this experiment.

Part of this work was performed in collaboration with Mr. J.B. Park and Mr. Y.J. Park, assistant of Nuclear Engineering Department, College of Engineering, Hanyang
University.

\section{References}

1) Lazarus, D.: In Solid State Physics, edited by F. Seitz \& D. Turnball, Vol. 10, p. 71, Academic Press Inc., New York (1966)

2) Yook, C.C.: J. of Nuclear Sci., Korea, 6, 68 (1966)

3) Crank, J.: Mathematics of Diffusion, p. 11, Oxford Univ. Press, London, (1957)

4) Peterson, N. L. \& Rothman S. J.: Phys. Rev., 136, (3A) (1964)

5) Faircloth, R.L.: Proceeding of a symposium, Vienna IAEA, 22-27, July, Thermodynamics Vol. II, p. 141 (1965)

6) Shewman, P.G. \& Choi J.Y.: Trans. Met. Soc., AIME, 223, 589 (1962)

7) Keng, P., Chieh Wing : ASME Series, 10, 504 (1963)

8) Okkerse, B.: Phys. Rev., 103, (5) 1246(1956)

9) Choi, J.Y.: J.of KIME. Engr., Inc., 1, (2) 154 (1966)

10) Darken, L.S.: Trans. Met. Soc., AIME, 227, 654 (1961)

11) Choi, J.Y.: Heat Treatment of Metals, Moon Woon Dang Co., p. 145 (1966)

要旨

\title{
溶融 Aluminum 内における低炭素鋼の拡散
}

\author{
陸鐘 澈 \\ 韓国ソウル漠陽大学校工科大学原子力科
}

\begin{abstract}
溶融アルミニウム内で $0.01 \%$ 低炭素含有鉄球の拡散係数を tracer-diffusion 方程式と autoradiography 方法により求め得た。温度 $700^{\circ} \mathrm{C}, 750^{\circ} \mathrm{C}, 800^{\circ} \mathrm{C}, 850^{\circ} \mathrm{C}, 900^{\circ} \mathrm{C}$ に対し10分間拡散させ, 冷却 後試料を切削方式により切削し，熱中性子束 $0.877 \times 10^{12}$ neutron $/ \mathrm{cm}^{2} / \mathrm{sec}$ の間歇的な照射により 放射化し， ${ }^{59} \mathrm{Fe}$ の放射能を autoradiography で表わし, 光電密度により標準化したフィルムと比 較して放射能に換算し, tracer-diffusion 方程式である $A(x, t)=A_{0} /(\pi D t)^{1 / 2} \exp \left(-X_{n}^{2} / 4 D t\right)$ を利 用し, 試料中の $\mathrm{Fe}$ の拡散距離に対する放射能の強度変化を求め, 各温度に対する拡散係数 $D_{t}$ を 求めた。この $D_{t}$ は Arrhnenius type 方程式である $D_{t}=D_{0} \exp (-Q / R T)$ から活性化エネルギー $Q$ と entropy 項 $D_{0}$ の值を求めると $D_{0}=2.57 \times 10^{-3} \mathrm{~cm}^{2} / \mathrm{sec}, Q=4,600 \mathrm{cal} / \mathrm{mole}$ になった。
\end{abstract}

